\title{
AC3: A Novel Gene Plays a Role in the Regulation of Body Weight
}

\author{
Harvest F. $\mathrm{Gu}^{*}$ \\ Rolf Luft Center for Diabetes Research, Department of Molecular Medicine and Surgery, Karolinska Institutet, \\ Karolinska University Hospital (Solna), Stockholm, Se-171 76, Sweden
}

\begin{abstract}
AC3 is one of adenylyl cyclase isoforms involved in cAMP and insulin signaling pathway. A previous study using Goto-Kakizaki rat, a non-obese type 2 diabetes model, indicates that AC3 is over-expressed in pancreatic islets. A recent genetic study has demonstrated that AC3 DNA polymorphisms are associated with body mass index (BMI) in the subjects with obesity and type 2 diabetes. Furthermore, AC3 knock out mice exhibit obese when they age mainly due to low locomoter activity, hyperphagia and leptin insensitivity. These findings suggest that AC3 plays an important role in the regulation of body weight. This review summarizes genetic and biological relevancies of AC3 in the regulation of body weight and also discusses about the potential development of anti-obesity drug using AC3 as a target.
\end{abstract}

Keywords: Adenylyl cyclase 3, obesity, type 2 diabetes.

\section{INTRODUCTION}

Obesity and type 2 diabetes are complex diseases and are influenced by genetic and non-genetic (environmental and life-style) factors. Both diseases are recognized as conditions of growing biomedical importance to societies worldwide. Moreover, type 2 diabetes and obesity are connected. Approximately, $85 \%$ of the people diagnosed with type 2 diabetes are overweight [1-5]. Scientists have put the effort to search for susceptibility and resistance genes in obesity and type 2 diabetes. Genetic and functional analyses of the genes in both diseases will provide better knowledge of their patho-mechanisms and for future therapies [6].

\section{BIOINFORMATICS OF AC3}

Adenylyl cyclases (ACs or ADCYs) are enzymes that catalyze the synthesis of cyclic 3'5'-AMP (cAMP) from ATP. There are 10 closely related isoforms including ACs 19 and AC activating polypeptide 1 (ADCYAP1) that have been cloned and characterized in mammals [7]. AC3 (OMIM: 600291) is the third member in the AC family, and the aliases for AC3 gene are ATP pyrophosphate-lyase 3 and adenylate cyclases III. This gene is located in chromosome 2 p23.3 and spans 100,018 bases from the position of $24,895,542$ to $24,995,559$ bp (Reference ID numbers of g.DNA sequences are NC_000002.10 and NT_022184.14). AC3 mRNA (NM_004036.3) is 4,410 bp at length and the gene is widely expressed in various tissues including pancreatic islets, brain, heart, kidney, liver, lung and skeletal muscle. AC3 protein consists of 1,144 amino acids and the molecular weight is $128,960 \mathrm{Da}$. The protein consists of two trans-membrane regions $\mathrm{M} 1$ and $\mathrm{M} 2$, each containing six predicted membrane-spanning helices, and two cytoplasmic

\footnotetext{
*Address correspondence to this author at the Rolf Luft Center for Diabetes Research, Department of Molecular Medicine and Surgery, Karolinska Institutet, Karolinska University Hospital (Solna), Stockholm, Se-171 76, Sweden; Tel: +46 8 51779515; Fax: +46 8 51773658;

E-mail: harvest.gu@ki.se
}

regions $\mathrm{C} 1$ and $\mathrm{C} 2$. This membrane-associated enzyme catalyzes the formation of the secondary messenger cyclic adenosine monophosphate (cAMP), and is involved in a number of physiological and patho-physiological metabolic processes.

\section{AC3 EXPRESSION ANALYSIS WITH GK RAT}

Goto-Kakizaki (GK) rat is a non-obese Wistar substrain and develops type 2 diabetes early in life. The model was developed by Goto and Kakizaki at Tohoku University, Sendai, Japan in 1975. The GK rat exhibits moderate hyperglycaemia and markedly reduced glucose-induced insulin release in vivo, and in the isolated perfused pancreas and isolated islets. In addition to reduction of beta-cell mass, beta-cell defects have been found to associate with reduced insulin secretion, which are similarly evidenced by the studies in pancreatic islets isolated from type 2 diabetes patients. Therefore, GK rat is a useful animal model of type 2 diabetes [8-12].

The Stockholm GK rat colony was generated by 5 pairs of F40 generation of the Japanese colony in August 1989. Since then, research in diabetes with this animal model has been conducted in our department. A previous study from our laboratory has demonstrated that the AC3 mRNA was over-expressed in the pancreatic islets of GK rat, which was caused by two point mutations at positions $-28 \mathrm{~A} / \mathrm{G}$ and $358 \mathrm{~A} / \mathrm{C}$ of the promoter region. The insulinotropic effect of forskolin in GK rat islets is associated with an enhanced cAMP generation and with over-expression of AC3 mRNA [13]. Moreover, liver adenylyl cyclase activity was increased in the membranes of male ob/ob mice in comparison to the lean control mice [14]. These findings suggest a role for the AC3 gene in the pathogenesis of type 2 diabetes and obesity. Questions whether AC3 has genetic defect in type 2 diabetes patients and obese subjects are then taken into consideration. 


\section{GENETIC STUDY OF AC3 DNA POLYMORPHISMS}

In order to evaluate the genetic defect of $\mathrm{AC} 3$ in the development of type 2 diabetes and obesity, we have conducted a genetic association study for the AC3 gene in type 2 diabetes patients and obese subjects in a Swedish population [15]. Initially, we have carried out variation screening for the putative promoter region of human AC3 gene with a direct-sequencing analysis approach. A novel single nucleotide polymorphism (SNP) i.e. $-17 \mathrm{~A} / \mathrm{T}$ in the AC3 gene is identified. This promoter polymorphism has a relatively low minor allele (A) frequency. The A allele frequencies of this polymorphism in control subjects and type 2 diabetes patients were $4 \%$ and $8 \%$, respectively, which is less significant $(P=0.076)$. Subsequently, we have genotyped and analyzed additional 13 valid SNPs. We found that two SNPs, rs2033655 and rs1968482, had significant low minor allele frequencies in control subjects compared with all type 2 diabetes patients. Furthermore, these two SNPs are found to be strongly associated with obese subjects with NGT and obese type 2 diabetes patients (body mass index, BMI $\geq 30 \mathrm{~kg} / \mathrm{m}^{2}$ ). The association of these two polymorphisms with non-obese type 2 diabetes patients (BMI $\leq 26$ or $<30 \mathrm{~kg} / \mathrm{m}^{2}$ ), however, is found to be nonsignificant or of borderline significance. Moreover, the analyses for diplotypes constructed with these two polymorphisms also predict a significant association with BMI in obese subjects. Thus, this genetic association study provides the first evidence indicating that genomic DNA polymorphisms in the AC3 gene are associated with decreased BMI in Swedish subjects with and without diabetes.

\section{PHENOTYPES IN AC3 KNOCK OUT MICE}

Evidence from the genetic study suggests the interesting possibility that AC3 may play an important role in the regulation of body weight. To test this hypothesis, Wang et al. have generated a mouse model of AC3 deficiency [16]. The $\mathrm{AC}^{-/-}$mice right after birth are about half the size compared to wild type littermates mainly due to the lack of olfaction and pheromone responses which impair sucking. But, $\mathrm{AC}^{-1-}$ mice achieve similar size and weight as wild control mice after two months. Since then, $\mathrm{AC}^{-/-}$mice become obese. Adult male $\mathrm{AC}^{-/-}$mice are about $40 \%$ heavier than wild type male mice, while adult female $\mathrm{AC}^{-/-}$ mice are $70 \%$ heavier. The body weight gain is exclusively in fat mass but not in lean mass. Furthermore, Wang et al. have performed comparison analyses of serum leptin, insulin and triglyceride levels between $\mathrm{AC}^{-/-}$and $\mathrm{AC}^{+/+}$mice. Data indicate that serum leptin, insulin and triglyceride levels in $\mathrm{AC}^{-/ /}$are significantly increased compared to $\mathrm{AC}^{+/+}$mice.

Hypothalamus in brain has a functional role in appetite and body weight control. To explore the cellular mechanism of AC3 in the regulation of body weight, Wang et al. have measured $\mathrm{AC} 3$ activity in the hypothalamus of $\mathrm{AC}^{-/-}$mice and found that $\mathrm{AC} 3$ activity is decreased compared to $\mathrm{AC}^{+/+}$ mice [16]. Thus, observation of phenotypes of $\mathrm{AC}^{-/-}$mice is consistent with the genetic association study and indicates that AC3 plays an important role in the regulation of body weight. However, the patho-mechanism of $\mathrm{AC} 3$ in increasing risk of BMI is still not fully clear.

\section{KEY MESSAGES AND PERSPECTIVE}

From the studies of Wang et al. and ours, the key messages that we have learnt are: I. AC3 is over-expressed in pancreatic islets of non-obese and type 2 diabetes GK rat; II. AC3 genetic polymorphisms are associated with decreased risk of BMI; III. AC3 knock out mice become obese when they are adult, and IV. AC3 activity is reduced in hypothalamus while serum leptin, insulin and triglyceride levels are increased in $\mathrm{AC}^{-/-}$mice.

Evidence has indicated that $\mathrm{AC} 3$ plays an important in the regulation of body weight. But, we are still lack of knowledge concerning the pathway from hypothalamus to pancreatic islets and to adipose tissues. Very recently, new genetic loci including AC5, another isoform of AC family, are found to implicate in fasting glucose homeostasis. The AC5 genetic polymorphisms are associated with type 2 diabetes [17, 18]. Interestingly, both AC3 and AC5 are membrane-associated enzymes and activated/regulated by Gs $\alpha$ via forskolin, $\mathrm{Ca}^{2+} /$ calmodulin dependent protein kinase. Therefore, these two proteins have higher potentiality as targets for drug development. Further investigation of AC3 as well as AC5 in patho-physiology particularly in the pathway from hypothalamus to pancreatic islets and to adipose tissues has been taken into our consideration.

\section{REFERENCES}

[1] Kelly T, Yang W, Chen CS, Reynolds K, He J. Global burden of obesity in 2005 and projections to 2030. Int J Obes (Lond) 2008; 32: 1431-7.

[2] Wang Y, Beydoun MA, Liang L, Caballero B, Kumanyika SK. Will all Americans become overweight or obese? estimating the progression and cost of the US obesity epidemic. Obesity (Silver Spring) 2008; 16: 2323-30.

[3] Venables MC, Jeukendrup AE. Physical inactivity and obesity: links with insulin resistance and type 2 diabetes mellitus. Diabetes Metab Res Rev 2009; 25(Suppl 1): S18-23.

[4] Freeman H, Cox RD. Type 2 diabetes: a cocktail of genetic discovery. Hum Mol Genet 2006; (Suppl 2): R202-9.

[5] O'Rahilly S, Farooqi IS. Human obesity as a heritable disorder of the central control of energy balance. Int J Obes (Lond) 2008; 32(Supp1 7): S55-61.

[6] Vella A, Camilleri M. Pharmacogenetics: potential role in the treatment of diabetes and obesity. Expert Opin Pharmacother 2008; 9: 1109-19.

[7] Hanoune J, Defer N. Regulation and role of adenylyl cyclase isoforms. Annu Rev Pharmacol Toxicol 2001; 41: 145-7.

[8] Galli J, Li LS, Glaser A, et al. Genetic analysis of non-insulin dependent diabetes mellitus in the GK rat. Nat Genet 1996; 12: 317.

[9] Abdel-Halim SM, Guenifi A, Efendic S, Ostenson CG. Both somatostatin and insulin responses to glucose are impaired in the perfused pancreas of the spontaneously noninsulin-dependent diabetic GK (Goto-Kakizaki) rats. Acta Physiol Scand 1993; 148: 219-26.

[10] Abdel-Halim SM, Guenifi A, Luthman H, Grill V, Efendic S, Ostenson CG. Impact of diabetic inheritance on glucose tolerance and insulin secretion in spontaneously diabetic GK-Wistar rats. Diabetes 1994; 43: 281-8.

[11] Abdel-Halim SM, Guenifi A, Khan A, et al. Impaired coupling of glucose signal to the exocytotic machinery in diabetic GK rats: a defect ameliorated by cAMP. Diabetes 1996; 45: 934-40. 
[12] Ostenson CG, Efendic S. Islet gene expression and function in type 2 diabetes; studies in the Goto-Kakizaki rat and humans. Diabetes Obes Metab 2007; 9(Suppl 2): 180-6.

[13] Abdel-Halim SM, Guenifi A, He B, et al. Mutations in the promoter of adenylyl cyclase (AC)-III gene, overexpression of ACIII mRNA, and enhanced cAMP generation in islets from the spontaneously diabetic GK rat model of type 2 diabetes. Diabetes 1998; 47: 498-504.

[14] Begin-Heick N. Liver $\beta$-adrenergic receptors, $G$ proteins, and adenylyl cyclase activity in obesity-diabetes syndromes. Am J Physiol 1994; 94: C1664-72.
[15] Nordman S, Abulaiti A, Hilding A, et al. Genetic variation of the adenylyl cyclase 3 (AC3) locus and its influence on type 2 diabetes and obesity susceptibility in Swedish men. Int J Obes (Lond) 2008; 32(3): 407-12.

[16] Wang Z, Li V, Chan GC, et al. Adult type 3 adenylyl cyclasedeficient mice are obese. PLoS One 2009; 4: e6979.

[17] Dupuis J, Langenberg C, Prokopenko I, et al. New genetic loci implicated in fasting glucose homeostasis and their impact on type 2 diabetes risk. Nat Genet 2010; 42: 105-16.

[18] Saxena R, Hivert MF, Langenberg C, et al. Genetic variation in GIPR influences the glucose and insulin responses to an oral glucose challenge. Nat Genet 2010; 42: 142-8.

(C) Harvest F. Gu; Licensee Bentham Open.

This is an open access article licensed under the terms of the Creative Commons Attribution Non-Commercial License (http://creativecommons.org/licenses/by-nc/3.0/) which permits unrestricted, non-commercial use, distribution and reproduction in any medium, provided the work is properly cited. 